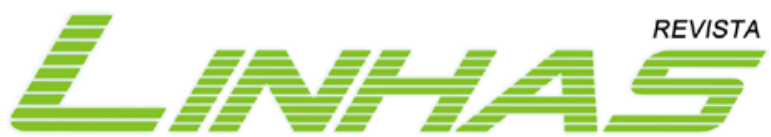

\title{
ARTICULAÇÕES ENTRE CURSOS DE FORMAÇÃO DE PROFESSORES, ESCOLAS E PROJETOS DE INCLUSÃO DIGITAL: possibilidades para a vivência plena da cultura digital
}

\author{
Joseilda Sampaio de Souza* \\ Maria Helena Silveira Bonilla**
}

\section{Resumo}

O artigo apresenta resultados da pesquisa de mestrado "Cultura digital e formação de professores: articulação entre os Projetos Irecê e Tabuleiro Digital”, realizada nos anos de 2009 e 2010, que investigou e analisou a possível interdependência entre dois projetos - um curso de pedagogia e um projeto de inclusão digital -, de modo a compreender a complementaridade na dinâmica de ambos, e identificar quais ações desenvolvidas por esses projetos possibilitaram a vivência e a formação da cultura digital entre os professores em formação. A investigação qualitativa e a natureza de estudo da etnopesquisa formação foram adotados enquanto perspectiva metodológica, e encontramos nos instrumentos - análise documental, observação participante e entrevistas semiestruturadas - os subsídios necessários para o desenvolvimento da pesquisa. Neste texto, procuramos analisar as ações desenvolvidas pelo curso de pedagogia, a fim de promover a articulação entre as escolas e o projeto de inclusão digital, apresentando e discutindo sobre o movimento de constituição e vivência da cultura digital que foi desencadeado na cidade de Irecê-Ba.

Palavras-chave: Cultura digital. Formação de professores. Escola. Telecentro.

\section{ARTICULATIONS BETWEEN TEACHERS COLLEGES, SCHOOLS AND DIGITAL INCLUSION PROJECTS: possibilities for the complete experience of digital culture}

\author{
Abstract \\ The article presents when they resulted from the inquiry of master's degree " digital Culture and teachers' \\ formation: articulation between the Projects Irecê and Digital Tray ”, carried out in the years of 2009 and 2010,

\footnotetext{
* Mestre em Educação pelo Programa de Pós-Graduação em Educação da Faculdade de Educação da Universidade Federal da Bahia e membro do Grupo de Pesquisa Educação, Comunicação e Tecnologias - GEC. E-mail: sulesp@gmail.com.

** Professora Associada da Faculdade de Educação da Universidade Federal da Bahia. Doutora em Educação pela UFBA e vice-líder do Grupo de Pesquisa Educação, Comunicação e Tecnologias - GEC/UFBA. E-mail: bonillabr@gmail.com
} 
which investigated and analysed the possible interdependence between two projects - a course of pedagogy and a project of digital inclusion-, in way to understand the complementaridade in the dynamic one of both, and identifying which actions developed by these projects made possible the existence and the formation of the digital culture between the teachers in formation. The qualitative investigation and the nature of study of the etnopesquisa formation were adopted while it puts in perspective metodológica, and we find in the instruments documentary analysis, observation participant and semi-structured interviews - the necessary subsidies for the development of the inquiry. In this text, we try to analyse the actions developed by the course of pedagogy, in order to promote the articulation between the schools and the project of digital inclusion, presenting and talking about the movement of constitution and existence of the digital culture that was unleashed in the city of Irecê-Ba.

Keywords: Digital culture. Teachers' formation. School. Telecentro.

\section{Introdução}

As tecnologias da informação e comunicação estão trazendo mudanças significativas para o nosso cotidiano: nossos hábitos e nossas relações sociais e comunicacionais estão cada vez mais dependentes delas, que nos proporcionam formas diversas de acesso, armazenamento, aquisição e produção de informações. A relação que se tem estabelecido com essas tecnologias ao longo dos últimos anos tem sido inédita, na medida em que a quantidade, a velocidade e o modo como estas informações passam a ser criadas e difundidas vêm potencializando a emergência de novas formas de pensar, sentir, agir e conviver. No entanto, ao mesmo tempo, tal relação tem exigido também o desenvolvimento de diferentes e complexas habilidades, do senso crítico e da capacidade produtiva que garantam uma melhor compreensão e apropriação deste contexto e de suas reais possibilidades/dificuldades na promoção das relações interpessoais e da produção e compartilhamento de conhecimentos para todos os sujeitos.

Essas exigências postas aos sujeitos sociais demandam uma nova postura da escola e da universidade, uma vez que compete a essas instituições a formação de todos, em todas as etapas da vida e em todas as áreas. É função dessas instituições, hoje, ir além do tradicional processo de transmissão de informações e conhecimentos, e articular em sua prática pedagógica o contexto, as características e a cultura que se constitui em torno das tecnologias digitais. Articular o mundo de dentro da escola e da universidade com o mundo externo implica criar oportunidades para a vivência plena da cultura digital. Para Costa (2008), a cultura digital está associada à capacidade dos indivíduos em atuar com os inúmeros ambientes de informação que os cercam, e cresce com “os dispositivos computacionais, da inter-relação entre os homens, do relacionamento cotidiano com as máquinas e da obsessão pela interatividade” (COSTA, 2008, p. 81). 
Portanto, a cultura digital implica não apenas o uso de equipamentos e produtos, mas sobretudo, processos comunicacionais, de experiência, de vivências, de produção e de socialização dessas produções, numa perspectiva multidimensional e não-linear, que "influem diretamente sobre nossa atividade consciente, por exemplo, a necessidade de escolhas, a incerteza, as sugestões, o risco e a tomada de decisão diante do excesso de informações, produtos e serviços” (COSTA, 2008, p.19). Na cultura digital, a comunicação, a produção, a criação, a publicação e a participação são potencialmente viáveis a todos que nela estiverem imersos. Mas, evidentemente, inventar, criar, partilhar e comunicar implicam uma imersão curiosa, ativa e propositiva no cenário das redes tecnológicas presentes no nosso cotidiano.

Nesse contexto, a constituição da cultura digital implica processos formativos amplos, provocadores de novas aprendizagens, de colaboração, de autoria, especialmente dos professores, responsáveis pela formação da juventude. Cria-se, assim, segundo Pretto (2010), um círculo virtuoso de produção permanente, com as escolas ganhando centralidade nos processos educacionais, constituindo-se em um espaço de trocas e interações sociais, de experimentação, de convivência das diferentes culturas - local, global, digital, analógica - e de diálogo com o saber estabelecido. Esse diálogo entre as culturas e os saberes deve envolver a escola, a universidade, os professores, os alunos e a comunidade do entorno - seja esse o "pequeno” entorno físico ao redor da escola, seja o “enorme” universo das redes sociais e tecnológicas.

Entender esse cenário e pensá-lo no sentido de que se possa explorar o seu potencial tem sido algo relevante no processo formativo de professores e estudantes. É neste sentido que, hoje, grande parte das reflexões acerca da formação de professores gravita em torno das análises das mudanças trazidas pela cultura digital e suas relações no que diz respeito à constituição das pessoas, à convivência entre elas e à criação coletiva de saberes diversos. Assim, foi a partir da necessidade urgente de repensar o processo de formação de professores no contexto da cultura digital que buscamos estudar, através da pesquisa de mestrado, um curso que, desde sua proposta, procura agregar projetos e ações que possibilitem o fortalecimento de tal processo, a partir da oportunidade de vivência e aprendizagem na cultura digital.

O texto apresenta alguns resultados da pesquisa: "Cultura digital e formação de professores: articulação entre os Projetos Irecê e Tabuleiro Digital”, realizada nos anos de 2009 e 2010, que teve como finalidade investigar e analisar a possível interdependência entre dois projetos - um curso de Pedagogia vinculado a um Programa de Formação de Professores e um projeto de inclusão digital -, de modo a compreender a complementaridade da dinâmica 
de ambos, e identificar quais ações desenvolvidas por esses projetos possibilitam a vivência e a formação da cultura digital entre os professores em formação.

A pesquisa, de natureza exploratória, realizada na cidade de Irecê-Ba, envolveu os professores em formação no curso de Pedagogia e seus alunos, sujeitos interagentes de um projeto de inclusão digital. O caminho metodológico adotado situa-se nas proposições da abordagem qualitativa, utilizando como natureza de estudo a etnopesquisa formação, que requer do pesquisador reflexões sobre seu processo formativo juntamente com os membros do grupo pesquisado. Segundo autores como Josso (2004) e Macedo (2006), a etnopesquisa formação possibilita uma experiência formadora que articula saber fazer, conhecimentos, funcionalidade e significados, técnicas e valores num espaço-tempo, que oferece a cada um a oportunidade de uma presença para si e para a situação vivida/pesquisada.

Dessa forma, tomamos como instrumentos para coleta de informações e reflexão: a análise documental, através dos documentos formulados para a proposta de formação dos professores e do projeto de inclusão digital; a observação participante, realizada em duas escolas públicas municipais bem como no projeto de inclusão digital, e de entrevistas semiestruturadas com dois professores-cursistas, uma diretora-cursista, coordenadores do curso, duas turmas de estudantes-alunos desses professores-cursistas e a secretária de educação do município.

O nosso objetivo neste texto é analisar as ações desenvolvidas pelo curso de pedagogia, a fim de promover a articulação entre as escolas e o projeto de inclusão digital, apresentando e discutindo sobre o movimento de cultura digital que foi desencadeado na cidade a partir desse processo.

\section{Contextualizando os projetos: o curso de Pedagogia e o projeto de inclusão digital}

A Universidade Federal da Bahia (UFBA), a fim de contribuir, através de ações significativas no estado da Bahia, com o esforço nacional empreendido na qualificação de professores, vem desenvolvendo, através do Programa Especial de Graduação da Faculdade de Educação (Faced/UFBA), cursos de formação de professores em diferentes cidades. Este programa, em parceria com as secretarias de educação desses municípios, e respeitando as singularidades locais, vem implementando tais cursos em Salvador, Tapiramutá e Irecê, a partir de projetos que levam os nomes dessas cidades.

O Curso de Pedagogia do Programa de Formação Continuada de Professores da 
Faced/UFBA, para os professores de Irecê, denominado Projeto Irecê, teve início com a proposta da Secretaria de Educação desta cidade, encaminhada formalmente à Faculdade de Educação da UFBA, em novembro de 2001. Na elaboração deste projeto formativo, a faculdade buscou atender às demandas sociais expressas nas políticas públicas atuais direcionadas para o campo da qualificação de professores. Para tanto, foram previamente realizadas "visitas, palestras, oficinas, reuniões de trabalhos, assim como uma coleta de dados sobre os diversos aspectos educacionais e de outros setores de influência do município” (FACED, 2003).

Na sua concepção, o Projeto Irecê apresentou as dimensões da informação e do conhecimento e a dinâmica espaço-temporal em uma perspectiva em que "a ação docente deve contemplar, concomitantemente, aspectos individuais de auto-realização e plenitude, e aspectos sociais, contribuindo, assim, para realizar um movimento conhecido como “cidadania planetária"”, no qual as questões éticas sejam recuperadas” (FACED, 2003, p.8). Então, em janeiro de 2004, o Projeto Irecê iniciou suas atividades com a primeira turma, abrangendo professores, coordenadores e gestores escolares, perfazendo um total de 146 cursistas matriculados, buscando promover a formação em nível superior dos educadores em serviço da rede municipal de Irecê. Já no ano de 2008, uma segunda turma foi formada, contemplando, então, mais 60 cursistas, dando continuidade ao processo formativo.

Este projeto, ao longo dos anos, desenvolveu a formação continuada de professores em serviço como eixo norteador do curso, buscando garantir que o processo de formação e a produção de conhecimentos fossem construídos em conjunto pelas comunidades escolar e acadêmica. O curso apresenta duração de três anos, com uma organização currricular diferenciada, prevendo momentos formativos que acontecem em ciclos - que cronologicamente correspondem ao semestre letivo da UFBA. As discussões e ações promovidas durante esta formação têm repercutido no trabalho de cada professor em sala de aula, ao mesmo tempo em que as práticas do cotidiano escolar servem de base para as discussões e atividades acadêmicas.

O diferencial encontrado nessa proposta de formação de professores é o fato de trazer uma concepção curricular inserida na lógica hipertextual e na dinâmica em rede, potencializando aspectos importantes de um currículo aberto, inovador, flexível, favorecendo

\footnotetext{
${ }^{1}$ Para Moacir Gadotti (1998) educar para a cidadania planetária supõe o reconhecimento de uma comunidade global, em que as exigências da sociedade devem ser trabalhadas pedagogicamente a partir da vida cotidiana, das necessidades e interesses das pessoas. Em concordância com este autor, Francisco Gutiérrez (1997) supõe o desenvolvimento de novas capacidades, tais como: imaginar, inventar, criar e recriar; relacionar e inter-conectarse, auto-organizar-se; informar-se, comunicar-se, expressar-se, entre outras.
} 
a hipertextualidade, a cooperação e a sincronicidade na aprendizagem. Dessa forma, são oferecidos conjuntos de atividades curriculares $^{2}$, disponibilizadas e implementadas especificamente para aqueles ciclos em vigor, mas que podem se repetir em momentos posteriores. A proposta curricular do Projeto Irecê possibilita a cada professor-cursista realizar suas escolhas individuais, cursando as diversas atividades com as quais se identifica. Importa destacar que as escolhas das atividades são realizadas de forma orientada, atendendo, assim, ao mesmo tempo, aos interesses acadêmico-pedagógicos e à construção do percurso de aprendizagem de cada professor-cursista. Notamos que essa dinâmica favorece a autonomia do professor-cursista - que assume a responsabilidade da sua formação - e tem alterado o processo de ensino e aprendizagem, com uma experiência mais horizontalizada no cenário formativo desses professores.

As atividades curriculares variam em conteúdos/formas, e são, intencionalmente, oferecidas de forma não obrigatória, atendendo, contudo, às determinações de distribuição de carga horária, respeitando as orientações legais da UFBA. Como proposta formativa, tais atividades são apresentadas tomando como referência os eixos temáticos que respaldam teoricamente os percursos curriculares e reúnem as abordagens conceituais e os temas de diversas áreas de conhecimento, tais como: educação e o conhecimento ao longo da história; Educação e práticas de ensino/pesquisa; Educação e linguagens; Educação e práticas docentes e, por fim, Educação e políticas públicas. Ao final do caminho formativo do programa de formação de professores, é esperado que cada professor-cursista tenha cumprido uma carga horária média de 500 horas em cada eixo, diversificando, assim, sua aprendizagem, a partir da compreensão de questões atuais, fundamentais, para sua formação.

Outro importante elemento a se destacar na proposta formativa do Projeto Irecê é que o percurso formativo não acontece única e exclusivamente dentro do espaço escolar, mas inclui, também, a integração com diferentes projetos, "articulando a educação, a comunicação, a saúde, o ambiente, a arquitetura e o urbanismo, entre tantas outras áreas” (FACED, 2003, p. 5). A construção de tais projetos, visando à inter-relação entre eles, apresentou a intencionalidade de envolver o contexto socioeducativo do município de Irecê, tendo a formação dos professores como base e contemplando "a diversidade de perspectivas, a polifonia dos discursos e apropriação das tecnologias que estão a serviço do conhecimento contemporâneo” (FACED, 2003, p. 8). Neste sentido, a implementação desses projetos

\footnotetext{
2 As atividades curriculares são de naturezas diversas, vinculadas às diferentes linguagens, e os conteúdos/formas foram considerados, durante a elaboração do Projeto, como referências formativas imprescindíveis na formação dos cursistas.
} 
buscou desencadear mudanças capazes de transformar os cidadãos e cidadãs ireceenses em participantes ativos do processo formativo promovido no curso, e inseri-los na cultura digital, devendo ser "implementados, desenvolvidos e avaliados de forma interdependente" (FACED, 2003, p.8).

Uma dessas ações articuladas ao Projeto Irecê, com o objetivo de instalar espaços para a constituição da cultura digital, foi a implementação dos projetos Ponto de Cultura Ciberparque Anísio Teixeira e Tabuleiro Digital. Esses dois projetos - ambos constituídos com o apoio da Prefeitura Municipal de Irecê, tendo como parceiros, respectivamente, o Ministério da Cultura (MinC) e a Petrobras - foram assumidos pela Faculdade de Educação, através do Grupo de Pesquisa Educação, Comunicação e Tecnologias (GEC), como estruturantes das dinâmicas formativas dos educadores e possibilitando a integração das comunidades acadêmica e não acadêmica na cultura digital. Com sua implementação, o Ponto de Cultura passou a representar, para aquele município, um local em que a população encontra disponíveis estúdios de gravação e de produção multimídia para intensificar a produção de cultura local.

É preciso destacar que nem todos os projetos previstos para serem articulados à formação dos professores foram implementados. Porém, dentre aqueles cuja implementação foi assegurada, podemos afirmar que, no âmbito da cultura digital, o Ponto de Cultura Ciberparque Anísio Teixeira foi uma das ações que contribuiu e vem ainda contribuindo fortemente na formação dos professores-cursistas do Projeto Irecê. A idealização deste Ponto de Cultura aconteceu a partir da integração ao programa Cultura Viva, lançado pelo Ministério da Cultura (Minc) através de um edital aberto a todo o país. Este edital representou a possibilidade de instalação de espaço para a produção da cultura digital naquele município. Após a aprovação do projeto junto ao edital, através de uma atividade curricular oferecida no ciclo quatro da primeira turma do Projeto Irecê, denominada “Ponto de Cultura”, um grupo de 25 professores-cursistas planejaram as ações que seriam desenvolvidas nesse Projeto, construindo uma forte aliança entre a formação do professor, os alunos das escolas e a perspectiva de produção de cultura digital.

Assim, por meio das ações do Ponto de Cultura, foi implantado o Projeto Tabuleiro Digital, que se constituiu como um espaço público de acesso à rede mundial de computadores, oferecendo "atividades diversas à comunidade, incluindo a preocupação com a atualização constante dos professores” (FACED, 2003, p. 9). A implantação do Projeto Tabuleiro Digital, em março de 2006, ocupando a área pública interna da Secretaria de Educação de Irecê, se constituiu como uma ação inicial de inclusão digital para aquele município, uma vez que, 
depois, se espalharia, como que ganhando autonomia, pelas comunidades circunvizinhas. A intenção inicial dos formuladores do Projeto Tabuleiro Digital era que as estruturas físicas desses ambientes de acesso à internet "fossem de baixo custo e que trouxessem uma marca cultural muito forte” e que “o móvel, em si, desde o primeiro momento, já pudesse representar a dimensão conceitual desenvolvida” (BONILLA; PRETTO, 2007, p. 84). A ideia envolvia um dos traços culturais mais marcantes da Bahia, aquele em que um local cotidiano de encontro de pessoas se transforma em um espaço de comunicação, conhecimento e diversão. Daí a escolha de tabuleiros como esses móveis, pois, da mesma forma que encontramos uma diversidade de produtos nos tabuleiros das baianas do acarajé, simbolizados como um ponto de encontro e de troca de informação, o projeto, com seus tabuleiros, também representaria o acesso à diversidade de informação e conhecimentos através da internet.

Nesse sentido, a concepção da estrutura dos móveis do Projeto Tabuleiro Digital, obra do arquiteto Eduardo Rosseti, mestre em arquitetura pela Faculdade de Arquitetura da UFBA, foi pensada como um suporte para computadores, associado a uma lógica estrutural e a uma simplicidade funcional. As máquinas são apoiadas em suportes de madeira, e os tabuleiros possuem um desenho simples e de fácil execução, além de serem fáceis também na sua montagem e desmontagem, pois têm estrutura leve e quatro pés formando um $\mathrm{X}$, travados por um plano horizontal. Como afirma Pretto (2005a, p. 352), o Tabuleiro Digital “é reto, sem encostos, sem almofadas, projetado para uso rápido e ágil como o do tempo de comer um bom acarajé”, rompendo, assim, com a imagem das tradicionais linhas futuristas de móveis de aço escovado - os conhecidos totens - que, por conta do seu design sofisticado, se fixam no imaginário das pessoas como objeto quase inacessível ao sujeito comum.

A ideia desenvolvida pelos elaboradores do Projeto Tabuleiro Digital vem enfatizar a busca de tornar o uso da rede como algo cotidiano, ou seja, transformar o uso da internet em algo corriqueiro e, dessa maneira, aproximá-la das pessoas. Dessa forma, para o funcionamento do projeto em Irecê, foram dispostos 36 (trinta e seis) computadores conectados à internet, organizados em seis ilhas distribuídas em um espaço de $100 \mathrm{~m}^{2}$ construído especialmente para esse fim. Com o desenrolar do Projeto Tabuleiro Digital, este espaço se tornou um importante lugar de trocas, tanto para o processo formativo de professores, quanto para as interações professor/aluno, aluno/aluno e comunidade em geral, repercutindo positivamente no movimento de constituição da cultura digital no município de Irecê. Podemos afirmar que o Tabuleiro Digital obteve êxito nos seus objetivos, pois, concebido para fortalecer as dinâmicas formativas de educadores e da inserção da UFBA na cultura digital, tornou-se um projeto modelar, e se espalhou, como idealizado na sua 
elaboração, "ganhando autonomia, pela universidade e pelo estado da Bahia”" (BONILLA; PRETTO, 2007, p. 84).

\section{Uma triangulação possível: a escola, o Projeto Irecê e o Tabuleiro Digital}

Ao longo da pesquisa foi possível perceber a necessidade da escola, e consequentemente, dos professores, em incorporar as potencialidades advindas da interação favorecida pelos diversos ambientes virtuais explorados por seus jovens estudantes. Daí a necessidade de se estabelecer uma relação mais próxima entre a escola e os espaços que oferecem acesso às tecnologias, frequentados por esses jovens. Quando falamos desta aproximação, trazemos a experiência vivenciada no Projeto Irecê, o qual, por meio do processo formativo dos professores das escolas, efetivamente contribuiu para uma interrelação entre os jovens estudantes ireceenses e o Projeto Tabuleiro Digital.

Desde quando esse programa formativo começou a ser realizado em Irecê, até os dias atuais, sempre houve uma preocupação, por parte da coordenação do programa e da prefeitura, em criar condições e possibilidades para que estes diferentes projetos fossem desenvolvidos em um mesmo local. Dessa forma, foi disponibilizado, com o apoio da prefeitura, o Espaço UFBA, destinado tanto aos cursistas e professores do curso de Pedagogia, quanto aos outros habitantes do município, a fim de implementar uma infraestrutura tecnológica e cultural para que a formação desses professores-cursistas não estivesse centrada na lógica da transmissão de informação do formador para o cursista. Foram então construídos, neste espaço, diversos ambientes, como área de lazer, área verde, sala de vídeo-conferência, auditório equipado com recursos multimídia, laboratório de informática com acesso à internet, sala de reuniões, secretaria acadêmica, entre outros.

Como mencionamos, além de todos esses ambientes, o Programa de Formação de Professores de Irecê articulou, através do GEC da Faculdade de Educação da UFBA, a implantação do Ponto de Cultura Ciberparque Anísio Teixeira e do Tabuleiro Digital, disponibilizando, assim, espaços de acesso a computadores conectados à internet para a população do município.

\footnotetext{
${ }^{3}$ Atualmente, em Salvador, o Tabuleiro Digital está presente na UFBA - nas áreas externas da FACED e na Biblioteca Central - e no Centro Comunitário do bairro de Pirajá, através da parceria com o Projeto Onda Solidária de Inclusão Digital do Instituto de Matemática da UFBA. Além desses lugares, o Projeto é desenvolvido na cidade de Irecê, no espaço UFBA, e na UFRB, no Campus da cidade de Cachoeira, através da parceria com o PLUG (Programa de Disseminação do Software Livre em Escolas Públicas do Recôncavo da Bahia).
} 
Aqui se faz necessário, novamente, destacar que, desde o início, na proposição de suas ações, o Projeto Irecê previa ampliar as ações do curso, a fim de abranger os demais "espaços de aprendizagens, considerando todo o município de Irecê e os seus cidadãos e cidadãs como partícipes desse processo” (FACED, 2003, p.10). A Coordenadora-Geral do Projeto Irecê destacou, em entrevista concedida para a pesquisa de mestrado, que esse processo deveria tanto favorecer os professores em formação, quanto ser ampliado para outros contextos, estabelecendo uma “interferência na educação do município para além da formação do curso”. Nesse sentido, a abrangência das ações foi pensada a partir do desenvolvimento de diferentes projetos, os quais, a princípio, deveriam ser instalados, desenvolvidos e constantemente avaliados, principalmente, na sua interdependência com o Programa de Formação de Professores.

Em 2004, quando a UFBA chegou em Irecê, dando início às ações formativas, as condições de infraestrutura tecnológica deste município eram muito limitadas, de forma que os projetos - que deveriam ser agregados em seguida à implantação do programa de formação, atendendo às demais demandas formativas dos professores e da comunidade - só foram se tornando realidade de forma gradativa. Os depoimentos dos sujeitos envolvidos na implantação da primeira turma do Projeto Irecê mostram que a inserção da universidade na cidade e o desenvolvimento de suas ações influenciaram significativamente para a mudança desse contexto, tanto na inserção das tecnologias, quanto na incorporação de novos hábitos entre os seus habitantes em relação a estes recursos.

[...] como eu acompanhei todo esse processo desde a implantação da primeira turma do Projeto Irecê e da inauguração do Tabuleiro Digital, eu percebia que, antes, todos nós enfrentávamos muitas dificuldades. Depois da chegada desses espaços, houve uma busca muito grande pela aquisição de tecnologias entre os professores, nas escolas, com os alunos, e na própria cidade. (Professor-cursista1)

[...] antes, em Irecê, nós não tínhamos nem lojas que vendessem materiais de informática. Hoje encontramos outro cenário, que foi fortemente alterado, muito por conta do desenvolvimento das ações implementadas pela UFBA. (Professor-cursista2)

[...] o ciclo um da primeira turma foi um sufoco até para fazer a matrícula desses cursistas. O pessoal realmente não tinha noção - o computador não era difundido lá no interior. (Coordenadora-Geral Projeto Irecê)

Para a Coordenadora de Tecnologias, assim que foram iniciados os trabalhos no sentido de viabilizar o curso de formação dos professores proposto pelo Projeto Irecê, muitos desafios tiveram que ser enfrentados. O primeiro deles foi a organização do Espaço UFBA ambiente destinado, como já explicamos anteriormente, para a realização das atividades do 
curso e dos demais projetos a serem agregados a ele -, no qual seria instalado o laboratório de informática equipado com dez computadores conectados à internet. Devido aos impasses, de ordem política, encontrados nessa negociação com os parceiros do projeto, tal ambiente não foi viabilizado em tempo hábil, e a abertura do processo de aproximação, sensibilização e mobilização dos cursistas para o uso das tecnologias teve que acontecer fora deste espaço, nos laboratórios cedidos pela Universidade do Estado da Bahia (Uneb) e pela Fundação Bradesco.

É importante referenciar essa informação, por dois motivos. Primeiro, para mostrar o esforço dos idealizadores e colaboradores deste programa formativo para garantir sua implantação e implementação, assegurando, inclusive, que, antes mesmo da organização da estrutura física do curso, os professores em formação já fossem introduzidos no processo de vivência da cultura digital. Depois, para justificar o fato de que, por conta dessa e de inúmeras outras dificuldades enfrentadas, os projetos foram implantados gradativamente. Assim, após a estruturação do laboratório de informática do curso, no segundo semestre de 2004 - segundo ciclo do curso -, o objetivo era incorporar a vivência dos professores com as tecnologias à sua prática pedagógica. Então, a partir de 2006, o espaço Tabuleiro Digital foi inaugurado e incorporado ao processo formativo dos professores-cursistas e à prática pedagógica dos mesmos nas escolas em que atuavam, sustentando a concepção de qualificação em serviço deste curso, “que tem a práxis pedagógica como espaço de reflexão e como ação que dá sentido ao cotidiano escolar” (FACED, 2008). Para tanto, os professores cursistas desenvolviam ações, com seus jovens alunos, no espaço Tabuleiro Digital com o intuito de, ao mesmo tempo que promoviam a inserção de seus alunos na cultura digital, fortaleciam seus próprios processos formativos.

Esta integração provocou mudanças significativas nas dinâmicas pedagógicas desenvolvidas no interior das escolas. Pudemos observar que a aproximação desses projetos, além de integrar moradores e cursistas no espaço do Tabuleiro, motivou, principalmente, os professores-cursistas, em sala de aula, a compartilhar com seus estudantes as curiosidades, descobertas e aprendizagens acerca da cultura digital realizadas no seu processo formativo.

Consideramos que caso esses sujeitos não estivessem mobilizados no sentido de vivenciar a dinâmica do digital junto com seus estudantes, dificilmente buscariam imergir em projetos como o Tabuleiro Digital. Para confirmar esse argumento, em entrevista, a Coordenadora-Geral do Projeto Irecê, colocou que essa 
desenvolvido na cidade. Ou seja, o aluno da escola buscaria o Tabuleiro, mas não pela escola, e, sim, ele chegaria como um menino que está antenado para as novidades e para a curiosidade de descobrir coisas novas. E daí, pode ter certeza que o professor não teria o mesmo interesse! Se colocassem um Tabuleiro sem essas articulações, esse professor dificilmente iria buscá-lo apenas pela curiosidade. (Coordenadora-Geral do Projeto Irecê)

A instalação do Tabuleiro Digital coincidiu com o ciclo cinco da primeira turma do Projeto Irecê. A partir deste período, então, a triangulação entre este curso de formação, o Tabuleiro Digital e as escolas, prevista na elaboração destes projetos, foi sendo desenhada, tendo como protagonistas os próprios professores-cursistas, uma vez que, orientados por seus professores formadores, principalmente por aqueles que eram responsáveis pelas atividades que incorporavam a discussão sobre as tecnologias no curso, passaram a construir e desenvolver ações e práticas pedagógicas com as TIC para aplicar com seus estudantes em suas salas de aula. A primeira intenção nessa triangulação era incentivá-los a frequentar o Tabuleiro Digital e entrar em contato com os diferentes ambientes virtuais e seus inúmeros recursos. Assim, eles promoveram atividades que incitaram seus estudantes a realizar

[...] abertura de e-mail, blogs, joguinhos, familiarização com o ambiente, porque tínhamos crianças que nunca tinham contato! Então, tentamos movimentar os professores para que fizessem com que o Tabuleiro começasse a fazer parte do cotidiano das crianças do município. (Coordenadora de Tecnologias Projeto Irecê)

Essa triangulação que, inclusive, fortaleceu a articulação entre a dinâmica escolar e a universidade, uma vez que levou seus integrantes a desenvolver reflexões pedagógicas cada vez mais críticas, aos poucos foi sendo intensificada, e as dinâmicas desenvolvidas em torno desses projetos fizeram com que, gradativamente, o espaço do Tabuleiro Digital fosse completamente ocupado pelas crianças e pelos jovens, colaborando significativamente para que entrassem em contato com diversos recursos tecnológicos que quase nunca, ou mesmo nunca, eram explorados na escola, “fazendo a apropriação das tecnologias como elemento de cultura” (PRETTO, 2007, p.8).

Essa dinâmica oportunizou aos educadores de Irecê uma formação que buscava estabelecer relações entre o contexto social, a educação e as tecnologias da informação e comunicação, de modo a superar a lógica tecnicista, a qual, na maioria das vezes, apenas oferece treinamento aos indivíduos para aproveitá-los no mercado de trabalho. Tal dinâmica também oportunizou superar a perspectiva pedagogizante de uso das tecnologias na educação, que prevê o seu uso apenas para a transmissão dos conteúdos curriculares. Concordamos com 
Pretto (2007), ao ressaltar que precisamos desenvolver outra perspectiva de uso das tecnologias na educação, fortalecendo os processos de cultura digital, no sentido de superar a dicotomia:

para os filhos dos ricos, todas as condições, em um quarto conectado, com computadores, banda larga, suporte por 0800, e liberdade para fazer o que desejar e, para os filhos dos pobres, acesso aos telecentros, para ter aula de planilhas, processadores de textos ou coisa do tipo, geralmente muito entediante e fazendo com que as distâncias entre aqueles que têm acesso e os que não têm, aumente cada vez mais. (PRETTO, 2007, p. 8)

Esta reflexão de Pretto, em conjunto com nossas observações acerca das ações conjuntas dos Projetos Irecê e Tabuleiro Digital, viabilizadas principalmente pelos professores-cursistas enquanto desenvolviam seu processo formativo, e que favoreceram a apropriação do contexto digital por seus estudantes, nos levou a pensar na constituição de “culturas”, no plural, de forma que educadores e estudantes - todos eles aprendizes deixaram de ser meros consumidores de informação no seu processo educativo, para se tornarem, individual e coletivamente, autores e produtores de conhecimento e cultura. Destacamos que os educadores estavam se formando, explorando, aprendendo, descobrindo, produzindo e compartilhando novas informações, ao mesmo tempo que enfrentavam o desafio de articular a produção do seu conhecimento às diferenças, dificuldades, demandas e experiências trazidas por seus alunos.

A exploração/aproximação do contexto digital pelos jovens, no Tabuleiro Digital, foi fundamental para levar os professores-cursistas a adotar posturas diferenciadas, principalmente, ao trabalhar com as tecnologias digitais, superando os medos, as incertezas, colocando em prática o que estavam vivenciando no curso. É importante destacar, ainda, o esforço empreendido por estes educadores para aprender junto com seus jovens alunos, fato este que pudemos atestar através dos relatos postados em seus blogs:

[...] o resultado desta primeira visita ao TD foi de muita importância para mim e para meus alunos. Juntos, aprendemos, trocamos, e essa foi uma experiência maravilhosa. Eu que ainda não sabia como abrir uma página para realizar uma pesquisa na internet, pude aprender, naquele momento, junto com os meus alunos. (Blog do Professor-cursista da primeira turma, 2006) ${ }^{4}$

[...] a criançada parecia estar num mundo de conto de fadas, os olhinhos brilhavam, a timidez sumiu, as curiosidades afloraram, as crianças apáticas

\footnotetext{
${ }^{4}$ Relato disponível no blog - http://djaniraribeiro.zip.net, postagem em 30 de junho de 2006.
} 
falaram, mexeram, futucaram. E eu, junto com eles, pude aprender com cada descoberta. (Blog do Professor-cursista da primeira turma, 2009) ${ }^{5}$

As reflexões desses cursistas mostram que, enquanto os jovens dessa geração atual se apropriam facilmente das tecnologias digitais, porque estão crescendo com ela, "os professores estão se adaptando a elas - e isso não deixa de ser um tipo diferente e mais complexo de aprendizagem” (TAPSCOTT, 2010, p. 29). Nessa adaptação dos educadores, precisamos considerar que a falta de intimidade desses profissionais com estas mídias, na maioria das vezes, se justifica pelo fato destes profissionais terem sido educados numa cultura em que as tecnologias digitais não estavam presentes, ou seja, estes sujeitos se constituíram num contexto analógico e de escassez tecnológica, enquanto a geração atual, mesmo vivendo numa cidade do interior do nordeste brasileiro, com muitas dificuldades de acesso, busca interagir com as tecnologias digitais, sentindo-se à vontade e confortável com a lógica, os ambientes e os processos próprios desses dispositivos.

Dessa forma, podemos afirmar que a chegada das tecnologias da informação e comunicação na sociedade contemporânea mudou a ordem das coisas na escola, provocando uma subversão neste contexto educativo. Assim, o professor, ao aceitar participar de projetos como o Tabuleiro Digital para promover sua própria imersão e dos estudantes na cultura digital, precisa enfrentar o desafio de, em sala de aula, além de fazer uso constante das tecnologias digitais, aceitar aprender com seus alunos, trocando experiências e descobertas, tanto aquelas que obteve no seu processo formativo, como aquelas obtidas pelos seus estudantes nos seus diferentes contatos com estes dispositivos.

De acordo com Fantin (2010, p.14), a escola e os professores não podem deixar de considerar que "mesmo em condições adversas, crianças e jovens acessam as tecnologias, seja nas lan-houses ou noutros espaços sociais”. Daí entendermos que as propostas de articular os diferentes projetos nesse contexto formativo são desenvolvidas, inclusive, para desmistificar o caráter fetichista que envolve certos usos das mídias contemporâneas. Concordamos com a autora, ao afirmar que a complexidade que envolve a presença e o uso das tecnologias nas práticas educativas precisa estar articulada não só a uma reconfiguração da escola e seus espaços, mas, sobretudo, aos programas de formação inicial e continuada de professores.

O envolvimento dos professores nessa experiência formativa com o Tabuleiro Digital, em consonância com o Projeto Irecê, possibilitou aos professores perceber e discutir acerca do perfil profissional do educador nos cenários atuais, principalmente no que diz respeito a sua

\footnotetext{
${ }^{5}$ Relato disponível no blog http://minhasmemorias-vera.blogspot.com, titulo da postagem: Memorial - Voo na memória, reconstrução na história, em 02 de julho de 2009.
} 
relação com a cultura digital, mais especificamente com as mídias e as tecnologias digitais. Alguns dos professores-cursistas, em seus blogs, evidenciam essa percepção, ao expressar que:

[...] o meu papel não foi de transmitir conhecimento, e sim, criar um ambiente de inteligência coletiva, em que estavam colocadas as condições para os alunos e professores construir saberes. O ambiente criado pelos professores configura um espaço de diálogo, participação e aprendizagem. (Blog do Professor-cursista da primeira turma, 2006) ${ }^{6}$

É perceptível a repercussão desse projeto formativo no contexto educacional da cidade, de modo que o envolvimento dos professores na proposição de atividades específicas para vivenciar a cultura digital junto com seus alunos desencadeou um processo mais amplo, com as escolas se mobilizando para instalar laboratórios de informática, com conexão internet, e oferecer a seus alunos a vivência da cultura digital, sem a necessidade de deslocamento para outros espaços.

Dessa forma, o Projeto Tabuleiro Digital se constituiu, para a primeira turma do Programa de Formação de Professores, como "um braço da Faculdade. Nós enxergávamos Faculdade, Ponto de Cultura e Tabuleiro Digital juntos, então existia uma ligação muito forte entre ambos [...]” (Coordenadora-Local do Projeto Irecê) ${ }^{7}$. Já para a segunda turma, esse cenário foi um pouco modificado, visto que a maioria das escolas já havia organizado seus laboratórios, e o Tabuleiro deixou de ser amplamente requisitado. A partir de então, o projeto passou a desenvolver dinâmicas próprias, desvinculadas das ações realizadas pelos professores-cursistas:

o Ponto de Cultura e o Tabuleiro Digital terminaram ganhando uma vida própria. Estes projetos terminaram se transformando para Irecê uma referência do ponto de vista de política pública para o município. (Coordenador-Geral Ponto de Cultura e Tabuleiro Digital) ${ }^{8}$

Contribuiu para isso, também, o fato de que entre a finalização do processo formativo da primeira turma e o início da segunda turma, houve um intervalo de tempo, de aproximadamente um ano, sem o desenvolvimento das atividades do Programa de Formação

\footnotetext{
${ }^{6}$ Relato disponível no blog - http://djaniraribeiro.zip.net, postagem em 30 de junho de 2006.

${ }^{7} \mathrm{~A}$ coordenadora local do Projeto Irecê foi professora-cursista na primeira turma do curso e, por isso, apresenta em seu depoimento a sua concepção enquanto cursista que vivenciou esse processo, e agora o faz enquanto coordenadora que acompanha e gerencia o processo com outros professores.

${ }^{8}$ Entrevista realizada com o Coordenador-Geral e mentor do Ponto de Cultura Ciberparque Anísio Teixeira e Projeto Tabuleiro Digital, em 18 de junho de 2010.
} 
de Professores. Nesse intervalo, o Ponto de Cultura e o Tabuleiro Digital seguiram com suas ações voltadas para a comunidade, sem que estas, necessariamente, estivessem relacionadas às proposições do curso. Assim, o Tabuleiro Digital passou a fazer parte do cotidiano dos cidadãos ireceenses, independentemente de a universidade e os professores realizarem atividades de aproximação, e, dessa forma, o processo de articulação entre o curso e o Tabuleiro, que, no princípio, esteve bastante fortalecido, com o decorrer do tempo foi se fragilizando.

Por outro lado, os professores-cursistas da segunda turma do Projeto Irecê, assim como a turma anterior, tiveram garantida sua possibilidade de apropriação da cultura digital através das propostas desenvolvidas no curso. Com o término dos trabalhos com a primeira turma, os espaços de infraestrutura tecnológica do curso foram desfeitos, deixando os professores-cursistas da segunda turma e seus professores-formadores sem um lugar específico e adequado para iniciar as atividades de familiarização e uso das TIC. Então, o Projeto Tabuleiro Digital foi incorporado ao curso como espaço para a realização das atividades curriculares de tecnologias, e o Ponto de Cultura Ciberparque Anísio Teixeira passou a apoiar intensamente as ações formativas do curso, de forma que, nesta etapa, o Ponto de Cultura passou a ser considerado o braço forte da universidade, uma vez que conseguiu potencializar a cultura digital entre estes professores-cursistas, se constituindo como uma forte política pública que, concretamente, auxiliou esta turma no entendimento e na construção de dinâmicas em torno do contexto digital.

Aqui consideramos importante enfatizar que o Ponto de Cultura, em Irecê, representa um espaço disponibilizado à população para a produção da cultura digital, “através do fornecimento de recursos, equipamentos e consultoria para que a juventude tenha um local onde, com software livre, estejam disponíveis estúdio de gravação e de produção multimídia que intensificam a produção cultural e local” (PRETTO, 2005b, p. 343). Constatamos que este projeto, diferente do Tabuleiro, foi se materializando como espaço formativo para os professores desta turma em especial e também como ponte entre estes cursistas e seus estudantes e entre as escolas e a sociedade ireceense.

Tal materialização aconteceu porque as ações desenvolvidas pelo Ponto de Cultura associando fortemente os processos educacionais formais aos não formais, garantindo aos cidadãos do município de Irecê acesso livre ao universo tecnológico, à capacitação para a produção de bens culturais e fortalecimento da cidadania com participação democrática nos espaços públicos - possibilitaram a participação ativa dos professores no processo de acesso e 
apropriação dos meios de produção e formação cultural, tanto para si, como para seus estudantes.

\section{O movimento atual em torno da cultura digital no município de Irecê}

O Projeto Tabuleiro Digital configurou-se, na cidade de Irecê e em seu entorno, como um polo disseminador da cultura digital. Para o Coordenador-Local do projeto, é preciso considerar que "trouxe a possibilidade de as pessoas de baixa renda terem acesso à cultura digital”. A dinâmica desencadeada por seus usuários provocou um movimento que motivou a disseminação dessa cultura através de outros projetos, requeridos e demandados pela população.

Diferentemente do que aconteceu com a primeira turma, quando o espaço do projeto encontrava-se "quase todo tempo reservado para atuação das escolas, a fim de desenvolver alguma ação” (Coordenadora-Local Projeto Irecê), hoje, o cenário do Tabuleiro não conta mais com a presença constante dos cursistas. Contudo, esta mudança de contexto nos aponta outras possibilidades, pois a comunidade ireceence continua procurando este espaço/projeto, com iniciativas próprias, mantendo a cultura digital viva naquele município.

Não podemos deixar de considerar que as ações desencadeadas através da primeira turma do Projeto Irecê, que levaram os cursistas a desenvolver práticas pedagógicas com o uso das tecnologias digitais, trazendo seus jovens estudantes ao Tabuleiro Digital, transformaram-se em ações mobilizadoras para que as escolas buscassem alternativas para levar essa vivência para o seu interior e seu entorno. Dessa forma, as escolas municipais de Irecê, em parceria com a Secretaria de Educação, buscaram meios para equipar-se com infraestrutura tecnológica.

Segundo a Secretária de Educação, o município de Irecê possui atualmente em sua rede municipal um total de 34 escolas, dezoito delas na zona urbana e dezesseis situadas na zona rural. Desse total, somente três escolas, até o período de realização da pesquisa, não haviam sido contempladas com a inserção de computadores. Durante o período em que estávamos realizando a pesquisa de campo, pudemos acompanhar a chegada de cerca de duzentos computadores, frutos da adesão do município ao Programa Nacional de Tecnologia Educacional (ProInfo), destinados para dez escolas da zona urbana, ainda sem infraestrutura tecnológica. Ainda, de acordo com a secretária, futuramente as escolas da zona rural também serão contempladas com novos equipamentos. 
A inserção das tecnologias digitais nas escolas transferiu as dinâmicas que aconteciam no espaço do Tabuleiro para o interior dessas instituições. Compreendemos que, de certa forma, esta situação vem justificar a ausência de ações por parte dos professores-cursistas da segunda turma do Projeto Irecê junto ao Projeto Tabuleiro Digital, uma vez que a presença dos computadores nas escolas e as dificuldades de deslocamento das turmas, das escolas até o Tabuleiro, contribuíram para que, ao longo dos anos, os professores reduzissem as visitas com os estudantes ao projeto. Pelo que pudemos levantar junto aos professores-cursistas com os quais estivemos mais próximos durante a pesquisa de campo, hoje, esse movimento é quase inexistente, em decorrência das dificuldades encontradas.

[...] devido à distância, não tenho como levá-los ao Tabuleiro, então, eu procuro desenvolver atividades aqui na própria escola, pois nós temos um Centro de Inclusão Digital. Mas tenho alguns alunos que frequentam o Tabuleiro, mesmo que esporadicamente, quando os pais os levam. (Professor-cursista1)

A maior dificuldade é porque nós não temos transporte, a distância é muito grande para que possamos levar as crianças. Se dependesse deles (os jovens) nós iríamos até andando, se você pedir sugestões teremos várias: de bicicleta, de carroça, o que eles querem é ir! A Secretaria de Educação quer que façamos uso daquele espaço, enquanto não tivermos montado nosso laboratório, mas a escola e a prefeitura não têm transporte para facilitar esse processo. (Professor-cursista2)

Esses depoimentos mostram que o movimento por parte das escolas de levar seus estudantes ao Tabuleiro tem sido reduzido, principalmente, devido à distância entre as escolas e o espaço do Tabuleiro e à falta de transporte para locomoção neste percurso. Por outro lado, é preciso ressaltar que a ausência dos professores no Tabuleiro Digital não significa que a vivência da cultura digital diminuiu. Ao contrário, o que se percebe é que, na atualidade, o cenário desta cultura tem sido fortalecido - agora, no interior das escolas.

Concordamos com a coordenadora de tecnologias, ao afirmar que "praticamente todas as escolas estão com laboratório de informática, então, fica quase incoerente levar as crianças ao projeto, tendo que andar quilômetros e quilômetros para chegar ao mesmo, numa situação em que a prefeitura está enfrentando problemas de transporte para sua locomoção”. Aqui podemos analisar que a criação de outros espaços, de certa forma, tem atendido ao objetivo do Tabuleiro, que é, assim como os tabuleiros de acarajé, se espalhar por toda a cidade (CONEXÕES, 2006), como uma experiência ampliada para outros segmentos da sociedade interessados em levar a proposta adiante. 
No nosso entendimento, diante do que pudemos levantar durante o período de realização da pesquisa (2009-2010), foi possível identificar que o Projeto Tabuleiro Digital foi incorporado pela sociedade de Irecê, independente dos parceiros e dos propósitos iniciais. Ele se constitui como parte integrante da comunidade, o que para nós é bastante positivo, visto que provocou uma modificação na rotina da cidade, sendo “ocupado" tanto pela comunidade acadêmica, quanto pela não acadêmica, independentemente de ações programadas para que isso acontecesse. A presença do Projeto/Espaço Tabuleiro Digital neste município fortaleceu o movimento em torno da cultura digital, o que tem avançado a cada ano. Hoje é possível perceber que o projeto se tornou uma referência de proposta de inclusão digital na cidade: nesse ambiente, não importa a situação financeira, nem a condição de acesso de cada um, todos têm o seu espaço para navegar na internet e o utilizam do modo que desejam.

É em vista disso que percebemos que as ações desenvolvidas a partir da primeira turma do Projeto Irecê, envolvendo professores, escolas e estudantes, se constituíram em redes que foram se alastrando pela cidade, virtual e fisicamente, motivo que fortaleceu a integração e o uso dessas tecnologias como cultura. O potencial do ciberespaço tem sido explorado em uma perspectiva de "ambiente de circulação de discussões pluralistas, reforçando competências diferenciadas e aproveitando o caldo do conhecimento que é gerado a partir dos laços comunitários (LEMOS, 2002, p. 135). Para tanto, é possível observar que os jovens que frequentam o Tabuleiro e suas respectivas escolas - aquelas que visitamos e que estão estruturadas e se estruturando tecnologicamente - têm ganhado autonomia, mostrandose capazes de fazer uso dessas tecnologias, dialogando com o mundo a sua volta.

Entendemos que, na realidade, o que tem acontecido não é um afastamento dos professores-cursistas do Projeto Tabuleiro Digital. Nossa compreensão é de que a presença deste projeto na cidade colaborou no sentido de os professores proporem outras iniciativas que favorecessem a integração na cultura digital, a partir de suas escolas, comunidades e bairros. Uma dessas iniciativas está diretamente relacionada ao movimento do software livre, que também foi fortalecido e desenvolvido nos demais projetos da cidade, uma vez que a utilização deste sistema operacional, mais do que uma alternativa técnica e economicamente viável, se tornou, para este município, situado no interior nordestino, um exemplo de política pública, porque favoreceu e promoveu mudanças bastante significativas no que tange ao seu desenvolvimento tecnológico e cultural, envolvendo, inclusive, os gestores das unidades escolares e os administradores municipais no incremento de ações em uma perspectiva em que “a colaboração apresenta uma ênfase mais forte” (PRETTO, 2005a). 
Esse contexto nos fez entender que o desenvolvimento do trabalho colaborativo, proporcionado pelo processo formativo dos professores do Projeto Irecê, trouxe como objetivo romper com a perspectiva de consumo e de dependência tecnocultural. Constatamos que as primeiras intervenções em torno do software livre na cidade aconteceram por intermédio da Faced/UFBA, através das ações formativas, promovendo a discussão conceitual de forma que os cursistas pudessem conhecê-lo, colocando em cena a questão da autoria, da partilha, da cooperação e da colaboração. Dessa forma, este sistema operacional livre e aberto passou a ser estudado e utilizado nos espaços formativos do curso: o laboratório de informática, o Tabuleiro Digital e o Ponto de Cultura.

A partir do Ponto de Cultura, o software livre chegou às escolas, bairros e cidades próximas a Irecê. Pudemos observar que as intervenções do Ponto de Cultura foram determinantes para a disseminação e esclarecimento do software livre entre os cidadãos ireceenses, uma vez que foram promovidas

[...] oficinas de produções multimídias, palestras realizadas pela equipe de Culturas Digitais - regional nordeste em Irecê - assim como oferecemos curso de informática com iniciação em software livre na região de Irecê. Começamos com quatro turmas, cada uma com quinze alunos. E o maior evento promovido na cidade em torno desta discussão que foi a I Semana de Software Livre de Irecê, que aconteceu simultaneamente com a III Semana de Software Livre da Faced/UFBA ${ }^{9}$. (PROJETO CIBERPARQUE..., s/d).

Importa esclarecer, aqui, que o desenvolvimento dessas ações fortaleceu um movimento que estava se intensificando na Bahia, uma vez que, no processo formativo do curso de Pedagogia em Irecê, foram incorporadas as discussões que já aconteciam na Faculdade de Educação, através do Grupo de Pesquisa Educação, Comunicação e Tecnologias, "ao adotar como objeto de estudo a implementação de softwares livres, e, portanto, por meio desses estudos fomentou na Faced a prática da política de seu uso" (SAMPAIO, 2008, p. 11). Nesta direção, entendemos que a relação desse sistema livre e aberto não estava baseada única e exclusivamente no fomento ao desenvolvimento

\footnotetext{
${ }^{9}$ A III Semana de Software Livre da FACED teve como objetivo dar continuidade às ações do Projeto “Sou Livre Também!”, visando criar espaços para reflexão, discussão e vivências sobre Software Livre, Inclusão Digital e Formação de Professores. Nesta edição da Semana extrapolou-se o âmbito da Faculdade de Educação/UFBA, ao articular simultaneamente com outras comunidades para as discussões sobre essas temáticas, levando em conta as especificidades e necessidades de cada contexto envolvido. Assim, simultaneamente, aconteceu a I Semana de Software Livre de Irecê, que teve como objetivo ampliar as ações do Ponto de Cultura Ciberparque Anísio Teixeira, buscando mobilizar a comunidade ireceense para o debate sobre as questões relacionadas com o uso de software livre e os processos de apropriação tecnológicas e produção da cultura local. (III SSL, 2007)
} 
tecnológico, ou ainda, em uma percepção superficial de que basta usar software livre para fazer inclusão digital. A partir da experiência do curso e do trabalho desenvolvido pelo Ponto de Cultura, buscou-se fortalecer o desenvolvimento de campanhas, eventos de divulgação, conscientização e mobilizações em prol do software livre, ações de base para efetiva implantação deste, em diversas instituições na cidade. Para o Coordenador-Local do Tabuleiro Digital, o grande ganho ao aproximar tal discussão ao curso foi que este favoreceu

[...] um processo de formação relacionado ao conhecimento acerca do software livre. Muitos cursistas passaram a usá-lo depois de sua participação no curso, das atividades que eles realizaram conosco, aqui no Ponto de Cultura. Ou seja, a partir dessa inserção, você percebe a formação e a escolha consciente para o uso dos sistemas livres e abertos. (CoordenadorLocal Tabuleiro Digital)

Tal depoimento permite perceber que a opção e a adoção deste sistema operacional buscaram, sobretudo, estabelecer e fortalecer a constituição do acesso do cidadão ao conhecimento. Além disso, precisamos considerar que levar a discussão do software livre para uma cidade no interior de um estado, no momento em que estas discussões estavam sendo intensificadas no país, contribuiu significativamente para os avanços e para a concentração de pessoas em torno de uma questão que está voltada à diminuição de gastos públicos e ao compartilhamento de conhecimento. Em outras palavras, concordamos com Mello e Teixeira (2009), ao afirmarem que, quanto mais acessível estiver o software livre, mais teremos apoiadores aos projetos de inclusão e promoção da educação.

Dessa forma, o processo formativo proporcionado pelo Projeto Irecê passou a ser compartilhado e implementado em outras iniciativas na cidade, tendo a experiência do Tabuleiro como referência. Contando com o apoio do Ponto de Cultura, foram montados e instalados Telecentros Comunitários ${ }^{10}$ - projeto desenvolvido em parceria com o governo federal, que tem como objetivo incluir digitalmente todos os municípios brasileiros; Centros Digitais de Cidadania ${ }^{11}$ - projeto desenvolvido pelo governo do estado da Bahia, que apresenta como finalidade possibilitar ao cidadão, especialmente o de baixa renda, o livre

\footnotetext{
${ }^{10}$ Neste projeto os municípios selecionados recebem móveis e computadores, além de provimento de infraestrutura de rede lógica e de sistemas, instalação de softwares livres e de programas informatizados de gestão do telecentro. Em contrapartida, as prefeituras devem oferecer local adequado, com acesso à internet, luz, água potável, sanitários, linha telefônica e acessibilidade às pessoas portadoras de necessidades especiais.

${ }^{11}$ Os Centros Digitais de Cidadania são salas equipadas com microcomputadores, com uma série de softwares livres instalados, conectados à Internet banda larga. Esses computadores podem ser utilizados pelos usuários para acessar as páginas web, o correio eletrônico, produzir trabalhos e documentos, desenvolver estudos e pesquisas, bem como para capacitar-se, através dos cursos e oficinas oferecidos, no uso de programas de informática e da Internet.
} 
acesso às tecnologias de informação e comunicação.

Além dessas iniciativas, também foi feita a reestruturação dos Telecentros Banco do Brasil $^{12}$ - ação que se alinha com a política de responsabilidade socioambiental dessa instituição pública bancária, que começou com o processo de modernização de seu parque tecnológico, doando os equipamentos substituídos para comunidades carentes. Estes telecentros do Banco do Brasil foram implantados em comunidades rurais dos povoados de Itapicuru, Meia-Hora e Angical. Tais espaços foram montados com cerca de 10 computadores, todos rodando software livre, tendo como parceiros a Secretaria Municipal de Educação e o Grupo Irecê Linux (Gilix), este último trabalhando na formação dos monitores e da comunidade, realizando oficinas e cursos nos telecentros das comunidades vizinhas a Irecê.

Os projetos desenvolvidos nos povoados de Meia-hora e de Itapicuru foram ações desenvolvidas a partir de iniciativas de professores-cursistas. Estes projetos apresentam a mesma concepção de uso e de navegação do Tabuleiro Digital, que permite o acesso livre, com computadores configurados em software livre. No povoado de Meia-Hora, o Telecentro de Informática Anedia Moitinho Dourado surgiu para atender à demanda de integração à cultura digital dos estudantes, professoras e da comunidade em geral, pois o projeto está interligado à Escola Municipal Anita Marques Dourado. O desenvolvimento deste telecentro aconteceu a partir do projeto de gestão elaborado pela nova gestora da escola, que foi cursista da primeira turma do Projeto Irecê. Em depoimento para a pesquisa essa gestora nos relatou que a sua formação na UFBA instigou-a a levar para sua comunidade aquilo que estava vivenciando:

Eu queria que os jovens daqui de Meia-Hora também estivessem inseridos naquele contexto. Não é porque estávamos afastados do centro da cidade que a cultura digital seria inacessível para aqueles jovens. O curso nos impulsionou a fazer o uso autônomo e crítico das tecnologias digitais, e isso passou a ser também compartilhado com nossos alunos. (Diretora-cursista, aluna da primeira turma do Projeto Irecê)

Esse depoimento parece-nos bastante significativo, porque indica a importância que essa educadora atribui ao vínculo entre a cultura digital e a educação. Consideramos que a vivência desta cultura no seu processo formativo permitiu-lhe ressignificar ações e desenvolvê-las em prol da sua comunidade. Dessa forma, podemos concluir que a relação

\footnotetext{
${ }^{12}$ Segundo o site de inclusão digital do governo federal, este programa não se restringe à doação dos micros, mas também cuida da capacitação dos monitores e da articulação de parceiras, fomentando o desenvolvimento local. Os telecentros disponibilizam o acesso às tecnologias digitais, cursos em informática, serviços do Governo Eletrônico, digitalização e impressão de documentos, além de incentivar a pesquisa para preparação de trabalhos escolares. As entidades contempladas se responsabilizam pela gestão e administração dos espaços.
} 
estabelecida entre o Projeto Irecê e o Projeto Tabuleiro Digital configurou-se em uma marcante experiência, que trouxe mudanças expressivas para a escola, a cidade e para seus cidadãos.

No entanto, a principal transformação foi oportunizar que cada sujeito envolvido nesses projetos pudesse, efetivamente, “participar desse movimento, não sujeitando-se às práticas que o condicionam a mero consumidor, seja de informações, seja de bens, seja de cultura” (BONILLA, 2009, p. 197), o que nos fez compreender que os esforços empreendidos pelos professores formadores do Projeto Irecê estimularam a vontade desses cursistas em compartilhar suas aprendizagens e suas experiências com aqueles que estão sob a sua responsabilidade formativa.

\section{Referências}

BONILLA, M. H. S.Inclusão digital nas escolas. In: PINHEIRO, Antônio Carlos Ferreira; ANANIAS, Mauricéia (Orgs.). Educação, direitos humanos e inclusão social: histórias, memórias e políticas educacionais. João Pessoa: Editora Universitária da UFPB, 1 ed , v. 2, , 2009 (pp. 183-200).

BONILLA, M. H. S.; PRETTO, N. D. L. Formação de professores: as TIC estruturando dinâmicas curriculares horizontais. In: BOHUMILA, A.; FREITAS, K. S.(Orgs.). Educação a distância no contexto brasileiro: experiências em formação inicial e formação continuada. Salvador: ISP/UFBA, 2007 (pp. 73-92).

CONEXÕES, Ciberparque Anisio Teixeira. Faculdade de Educação - GRUPO DEPESQUISA EM EDUCAÇÃO COMUNICAÇÃO E TECNOLOGIA. 2006. Disponível em: <www.ici.ufba.br/twiki/pub/CiberParque/WebHome/projeto_ciberparque.pdf > . Acesso em: 17 ago. 2012.

COSTA, R. A cultura digital. São Paulo: Publifolha, 3 ed, 2008.

FACED. Programa de Formação Continuada de Professores, município de Irecê-BA. 2003. Disponível em:

<http://www.irece.faced.ufba.br/twiki/pub/UFBAIrece/WebPrograma/projeto_versao_atualiza da.pdf>. Acesso em: 07 jul. 2012.

FACED. Curso de licenciatura em Pedagogia - Ensino Fundamental/séries iniciais. Relatório Primeira Turma. Salvador, Julho 2008. Disponível em:

$<$ http://www.ici.ufba.br/twiki/pub/UFBAIrece/WebArquivos/Relat\%f3rio_final_11_08_08.do c>. Acesso em: 20 ago. 2012.

FANTIN, M. A escola e a cultura digital: os usos dos meios e os consumos culturais de professores. Anais XXXII Congresso Brasileiro de Ciências da Comunicação. Intercom: Comunicação, Educação e Cultura na Era Digital. Universidade Positivo, Universidade Federal do Paraná e Universidade Estadual do Centro Oeste do Paraná. Curitiba, 2009. 
Disponível em: http://www.intercom.org.br/papers/nacionais/2009/resumos/R4-2302-1.pdf > . Acesso em: 30 ago. 2012.

JOSSO, M. C. Experiências de vida e formação. São Paulo: Cortez, 2004.

LEMOS, A. Cibercultura: tecnologia e vida social na cultura contemporânea. Porto Alegre; Sulina, 2002.

MACEDO, R. S. Etnopesquisa crítica, etnopesquisa formação. Brasília: Liber Livro Editora, 2006.

MELLO, E. de F. F.; TEIXEIRA, A. C.. Um processo de inclusão digital na hipermodernidade. In.: TEIXEIRA, A. C.; MARCON, K. (Orgs). Inclusão digital: experiências, desafios e perspectivas. Passo fundo: Ed. Universidade de Passo Fundo, 2009 (pp.54-72).

PRETTO, N. D. L.. Comunicação, educação e tecnologias de informação e comunicação. In: MINASSIAN, Ara A.(Org.). Convergência \& interatividade: a tecnologia a favor do diálogo. Salvador: Irdeb, v.1, 2005 ${ }^{\text {(pp. 87-97). }}$

. Tabuleiro digital: educação e cultura digital. In. LEMOS, André (Org). Cibercidade II: Ciberurbe. A cidade na sociedade da informação. Rio de Janeiro: E-Papers, 2005b, (pp. 337-356).

. O papel da educação e o das políticas de cultura no desenvolvimento da Bahia.Salvador/Ba: SEI/Governo da Bahia, 2007. Disponível em:<www.ici.ufba.br/twiki/bin/view/GEC/SeiEduca Cultura >. Acesso em: 20 de ago. 2012.

Professores hackers e ativistas da rede. Revista ARede, ano 7, número 60, julho de 2010. Disponível em <http://www.arede.inf.br/inclusao/edicoes-anteriores/165-edicao60julho2010/3163-opiniao>. Acesso em 07 de mar de 2011.

SAMPAIO, J. S. Tabuleiro Digital: Vivências, dinâmicas e tensões. Um estudo de Caso. 106 f. 2008. Monografia (Curso de Pedagogia)- Faculdade de Educação, Universidade Federal da Bahia, Salvador, 2008.

TAPSCOTT, D. A hora da geração digital: como os jovens que cresceram usando a internet estão mudando tudo, das empresas aos governos. Rio de Janeiro: Agir Negócios, 2010. 